\title{
Multistation digisonde observations of equatorial spread $F$ in South America
}

\author{
B. W. Reinisch ${ }^{1}$, M. Abdu ${ }^{2}$, I. Batista ${ }^{2}$, G. S. Sales ${ }^{1}$, G. Khmyrov ${ }^{1}$, T. A. Bullett ${ }^{3}$, J. Chau ${ }^{4}$, and V. Rios ${ }^{5}$ \\ ${ }^{1}$ University of Massachusetts Lowell, 600 Suffolk St., Lowell MA 01854, USA \\ ${ }^{2}$ Instituto Nacional de Pesquisas Espaciais, Ave dos Astronautas 1758 C.P. 515 12202-970 Sao Jose dos Campos, SP, Brazil \\ ${ }^{3}$ Air Force Research Laboratory, 29 Randolph Road, Hanscom AFB, MA 01731, USA \\ ${ }^{4}$ Jicamarca Radio Observatory, Instituto Geofísico del Perú, Apartado 13-0207, Lima 13, Peru \\ ${ }^{5}$ University of Tucuman, Av. Independencia 1800, (4000) San Miguel de Tucuman, Argentina
}

Received: 8 December 2003 - Revised: 23 April 2004 - Accepted: 18 May 2004 - Published: 23 September 2004

Part of Special Issue "Equatorial and low latitude aeronomy"

\begin{abstract}
Directional ionogram and $F$-region drift observations were conducted at seven digisonde stations in South America during the COPEX campaign from October to December 2002. Five stations in Brazil, one in Argentina, and one in Peru, monitored the ionosphere across the continent to study the onset and development of $F$-region density depletions that cause equatorial spread $F$ (ESF). New ionosonde techniques quantitatively describe the prereversal uplifting of the $F$ layer at the magnetic equator and the eastward motion of the depletions over the stations. Three of the Brazilian stations were located along a field line with a $350-\mathrm{km}$ apex over the equator to investigate the relation of the occurrence of ESF and the presence of sporadic $E$-layers at the two $E$ region intersections of the field line. No simple correlation was found.
\end{abstract}

Key words. Ionosphere (equatorial ionosphere; ionospheric irregularities; instruments and techniques)

\section{Introduction}

To fully understand the processes that control the onset of equatorial spread $F$ it is helpful to investigate time development and spatial distribution of this $F$-region phenomenon. In support of the Brazilian COPEX campaign (Abdu et al., 2003), digisondes collecting ionogram and $F$-region drift data at seven sites in South America (Fig. 1). The sites are located within about $\pm 15^{\circ}$ magnetic latitude and cover about $30^{\circ}$ in longitude. The ionosondes typically recorded one multi-directional ionograms and a number of drift measurements every 5 min during the COPEX campaign period from October to December 2002. Three ionosondes were

Correspondence to: B. W. Reinisch

(Bodo_Reinisch@uml.edu) installed along a magnetic meridian with one sounder close to the magnetic equator (Cachimbo, $0.4^{\circ} \mathrm{N}$ magnetic), and the two other sounders (Boa Vista, $12.9^{\circ} \mathrm{N}$; Campo Grande, $-10.6^{\circ} \mathrm{N}$ magnetic) close to the intersections with the $E$ region of the 350-km field line over Cachimbo (Fig. 2). The objective was to study the influence that sporadic $E$-layers at the field line footprints may have on the formation of ESF at Cachimbo. Major characteristics of ESF in the South American longitude sector, and especially over Brazil, have been studied during the last two decades (see, for example, Abdu et al., 1998; Batista et al., 1990).

\section{Discussion}

\subsection{Signatures of low-latitude spread $F$ in ionograms}

The term "spread $F$ " was coined to give a visual description of the broadened echo traces seen on ionograms at certain times (Fig. 3). The equatorial spread $F$ (ESF) is usually associated with depletions in $F$-region densities, as shown by incoherent scatter radar (ISR) measurements at Jicamarca, Peru (e.g. Woodman and La Hoz, 1976; Anderson and Mendillo, 1983 and references therein). Sales et al. (1996) have used retracing to establish that the spread traces on equatorial region ionograms are the result of offvertical echoes that return from field-aligned irregularities in the depleted region, as identified by $630 \mathrm{~nm}$ all-sky images. Modern ionosondes operate essentially as radar systems, i.e. they measure radar distances and angles of arrival of the received echoes (Reinisch, 1996). In contrast to a conventional radar system, the ionosonde transmits a wide radio beam that illuminates a large area of several hundred $\mathrm{km}$ in diameter in the $F$-region, resulting in echoes returning from many directions in the presence of irregularities. With the introduction of Doppler interferometry to ionospheric sounding (Bibl and 


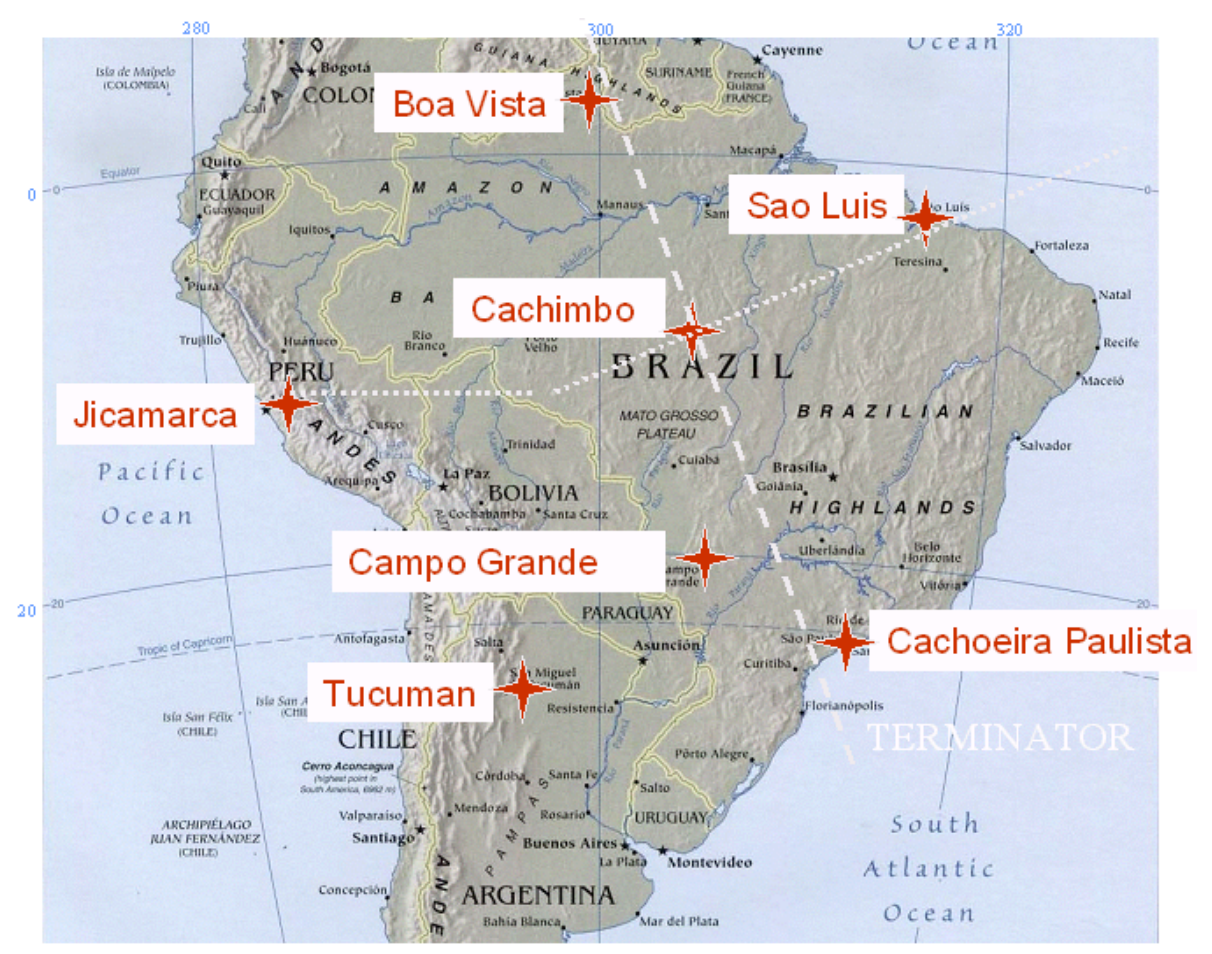

Fig. 1. Location of the seven digisondes in South America.

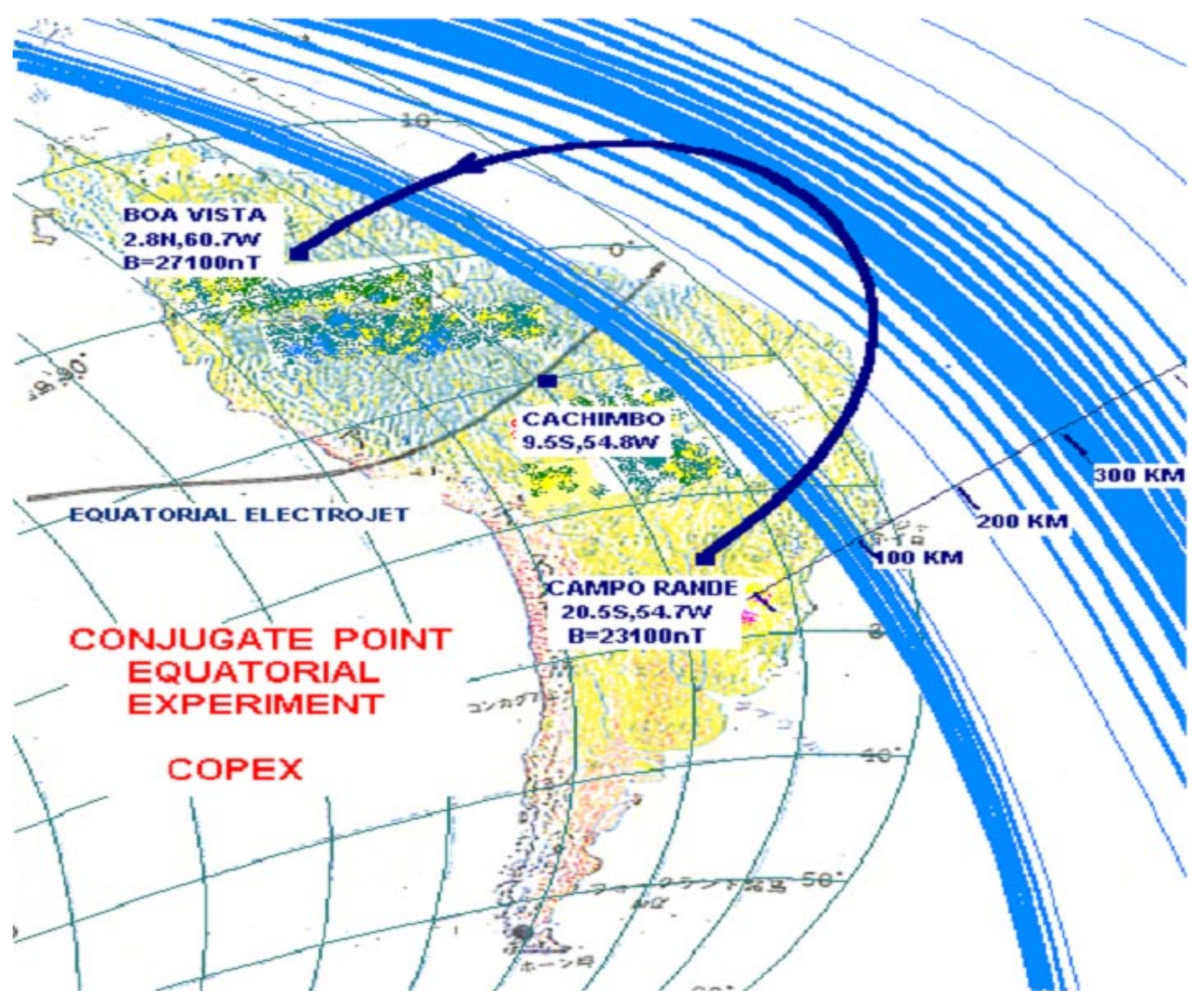

Fig. 2. The Brazilian COPEX stations at the equator (Cachimbo) and the conjugates stations at Boa Vista and Campo Grande. 


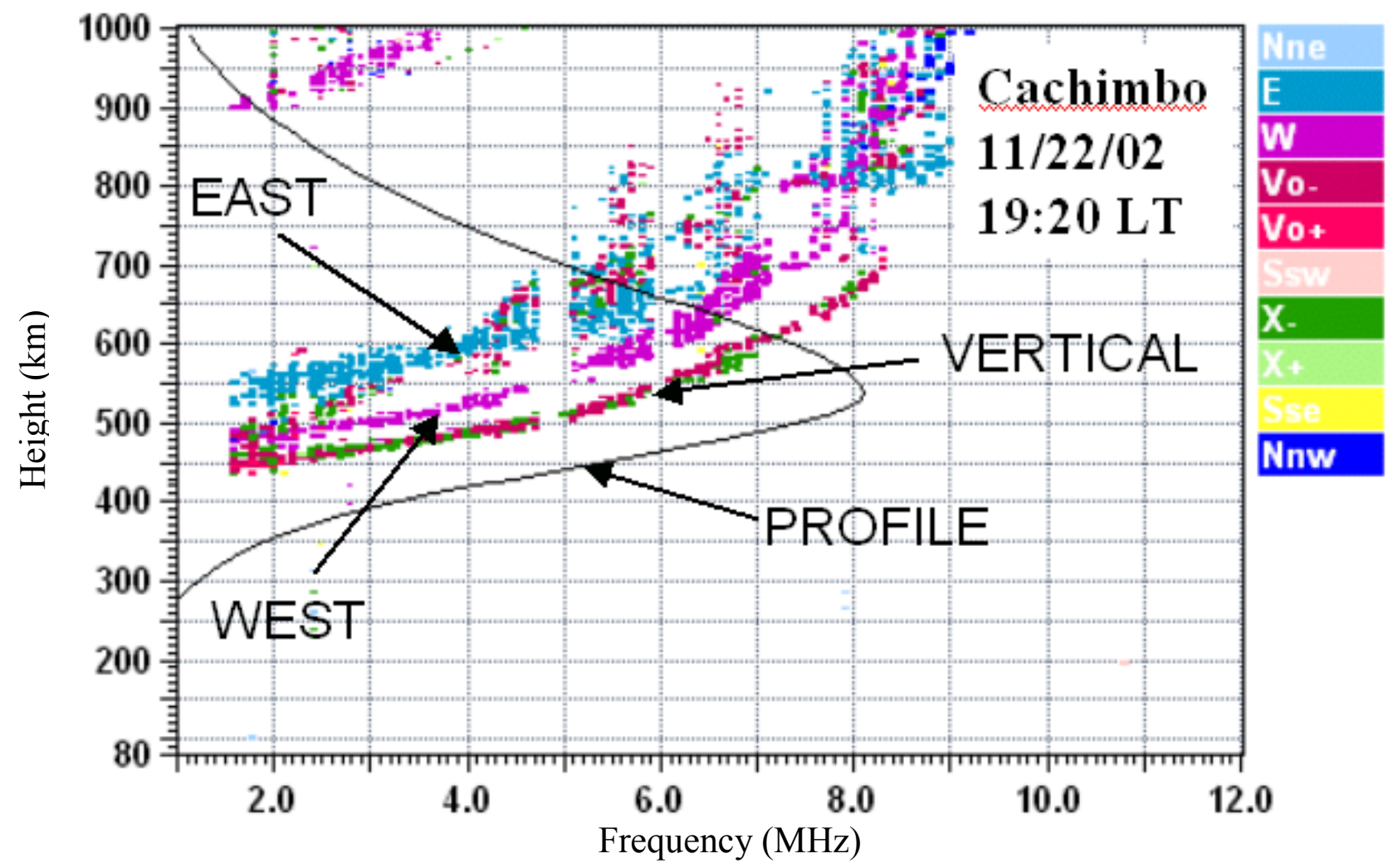

Fig. 3. Multi-directional ionogram at Cachimbo for 22 November at 19:20 LT showing echo traces from the west, east, and overhead, with an overlay of the vertical electron density (plasma frequency) profile.

Reinisch, 1978), it has become possible to identify the source regions of the spread echoes. The DPS digisondes use four small spaced antennas for signal reception arranged in a triangle with one antenna at the center. The signals from each antenna are Fourier analyzed to identify echoes with different Doppler frequencies.

Interferometry for each Doppler component then determines the source locations of the echoes, as illustrated by the high-resolution skymap in Fig. 4 observed at 19:13 LT, just a few minutes before the ionogram in Fig. 3 was recorded. The skymap, in geomagnetic coordinates, shows the locations of the $F$-region reflection points for frequencies between 3.8 and $5.3 \mathrm{MHz}$ from within a cone of $30^{\circ}$ around zenith; the colors indicate the Doppler shifts from $-2 \mathrm{~Hz}$ (red) to $+2 \mathrm{~Hz}$ (blue). The reflection points are distributed in the east-west direction, with Doppler frequencies of $-0.4 \mathrm{~Hz}$ in the west to $-2.0 \mathrm{~Hz}$ in the east. This Doppler frequency distribution suggests an upward and eastward drift velocity. The skymap measurements were repeated every $5 \mathrm{~min}$ to investigate the changing structure in the $F$-region and to determine the drift velocity components as a function of time. Figure 5 shows a subset of skymaps on 22 November 2002 for Cachimbo, spaced by $15 \mathrm{~min}$, starting at 17:23 LT. Each skymap is the result of a 20-s measurement at 4 frequencies between 3 and $5 \mathrm{MHz}$. The $F$-layer becomes tilted by about $5^{\circ}$ around 18:00 LT when the terminator moves over the station, and most reflection points are in the west.

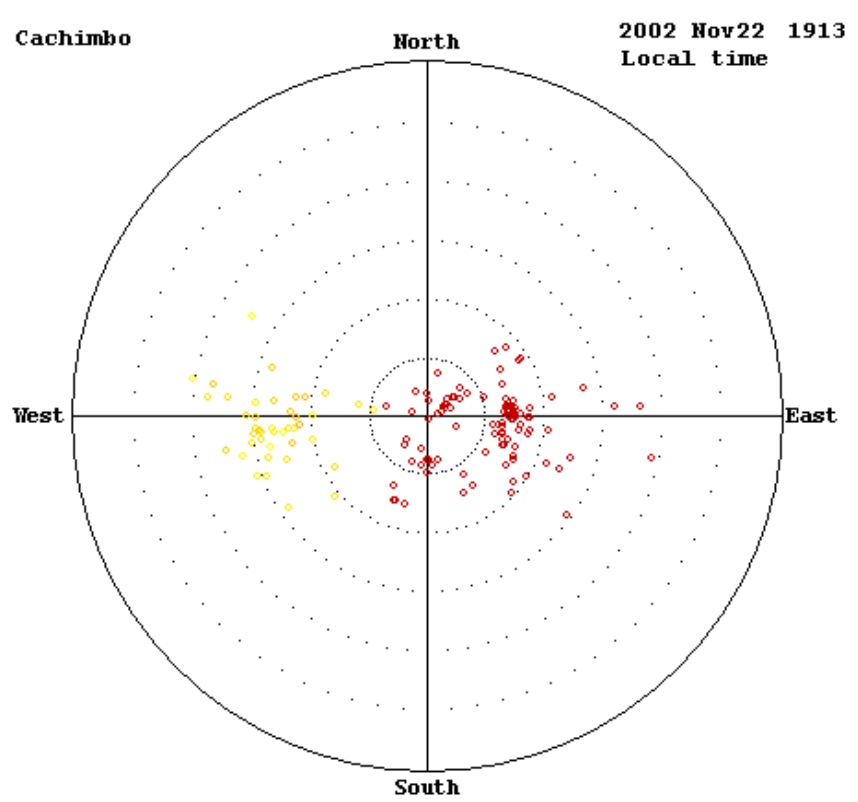

Fig. 4. Cachimbo skymap for 22 November at 19:13 LT showing echoes from the west with Doppler frequencies of $-0.5 \mathrm{~Hz}$, and from the east with Doppler frequencies of $-2.0 \mathrm{~Hz}$. The skymap displays zenith angles from 0 to $20^{\circ}$. 


\section{Cachimbo, 22 Nov 2002 (326), Local Time}

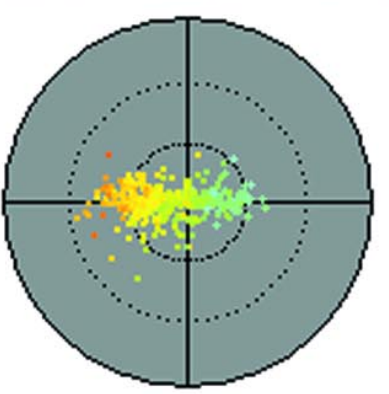

17:23

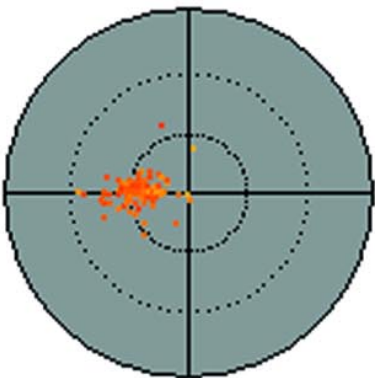

18:23

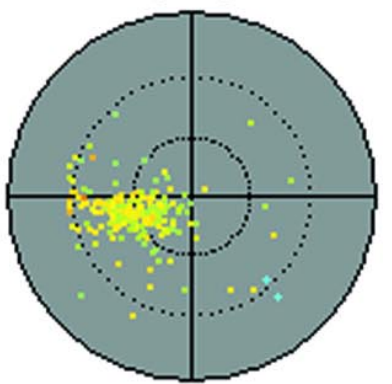

19:23

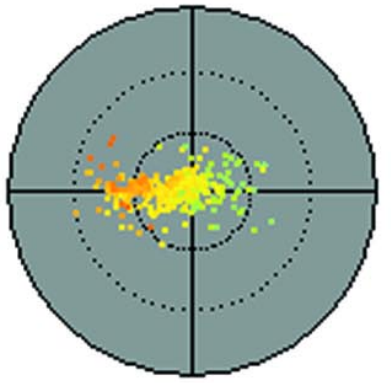

17:38

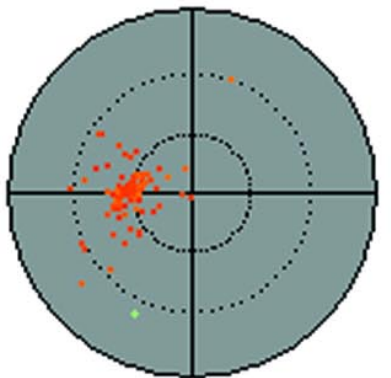

18:38

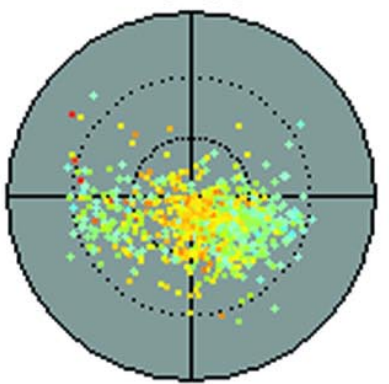

19:38

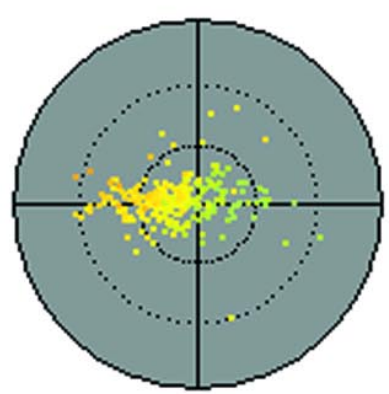

17:53

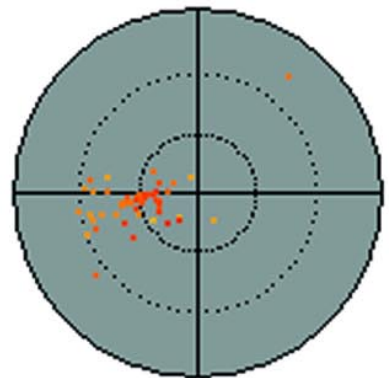

18:53

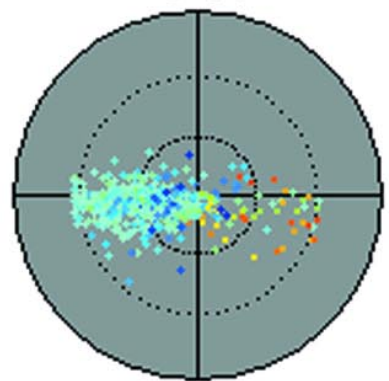

19:53

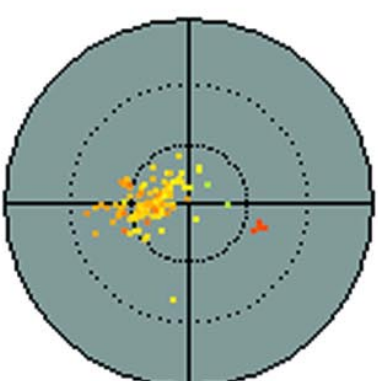

18:08

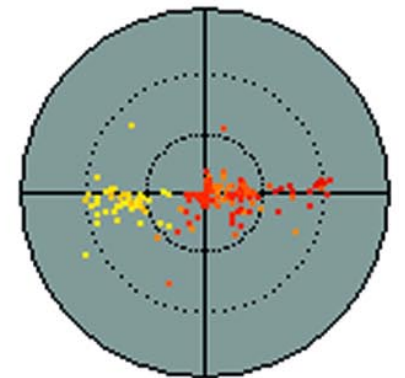

19:08

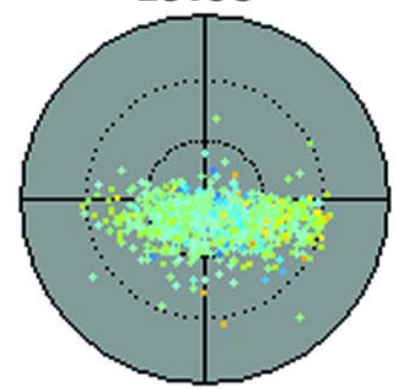

20:08

Fig. 5. Skymaps for Cachimbo on 22 November from 17:23 LT to 20:08 LT, showing the effect of the terminator passing at $\sim 18: 00$ LT.

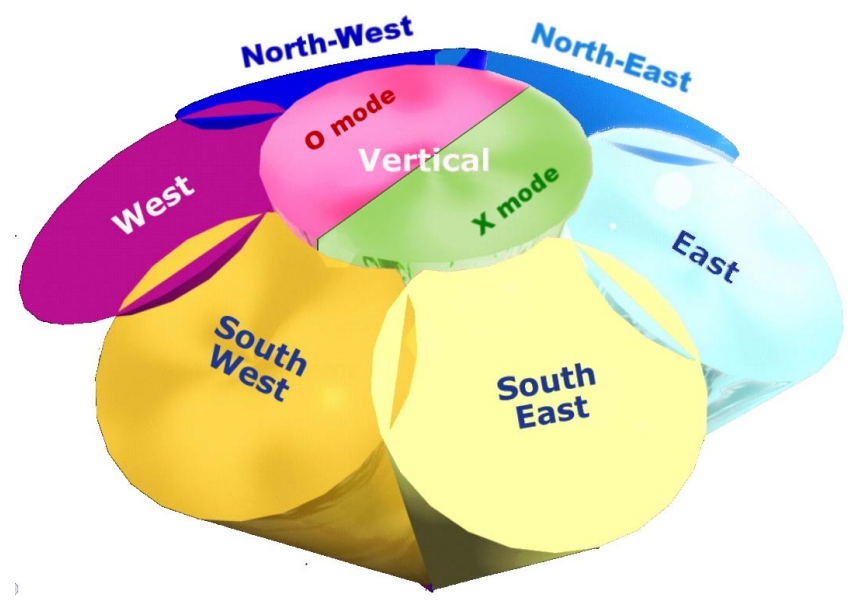

Fig. 6. Seven digitally synthesized beams for ionograms measurements.
For the ionogram display, the DPS synthesizes 7 beams pointing vertical and into six azimuthal directions at a selected fixed zenith angle, typically $20^{\circ}$ (Fig. 6). At each sounding frequency, the 7 digital beams are calculated for each range (height bin), resulting in an ensemble of 7 ordinary $(\mathrm{O})$ polarization ionograms and 7 extraordinary polarization $(\mathrm{X})$ ionograms. From the Fourier spectrum at each range, only the maximum spectral component is selected and the beam direction with the maximum synthesized amplitude is assigned to the range bin in the ionogram. The Cachimbo ionogram in Fig. 3 uses different colors to indicate the directions from which the echoes are arriving, clearly showing the composite nature of the equatorial spread $F$ ionograms, with $F$-region echoes arriving mainly from the west, east, and overhead in agreement with the skymap in Fig. 4. The overhead trace ( $\mathrm{O}$ echoes red, $\mathrm{X}$ echoes green) is used to calculate the vertical electron density profile up to $h m F 2$, superimposed on the ionogram as plasma frequency versus height (Huang and Reinisch, 2001). The topside part of the 
JICAMARCA

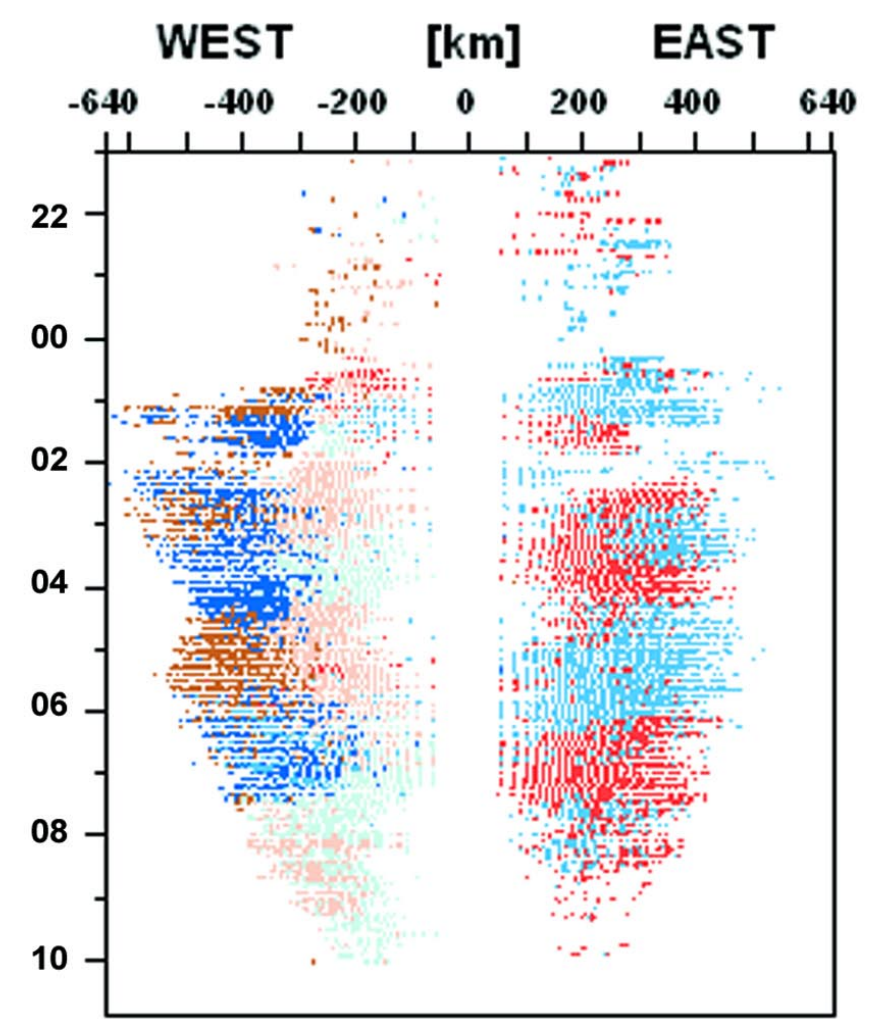

CACHIMBO

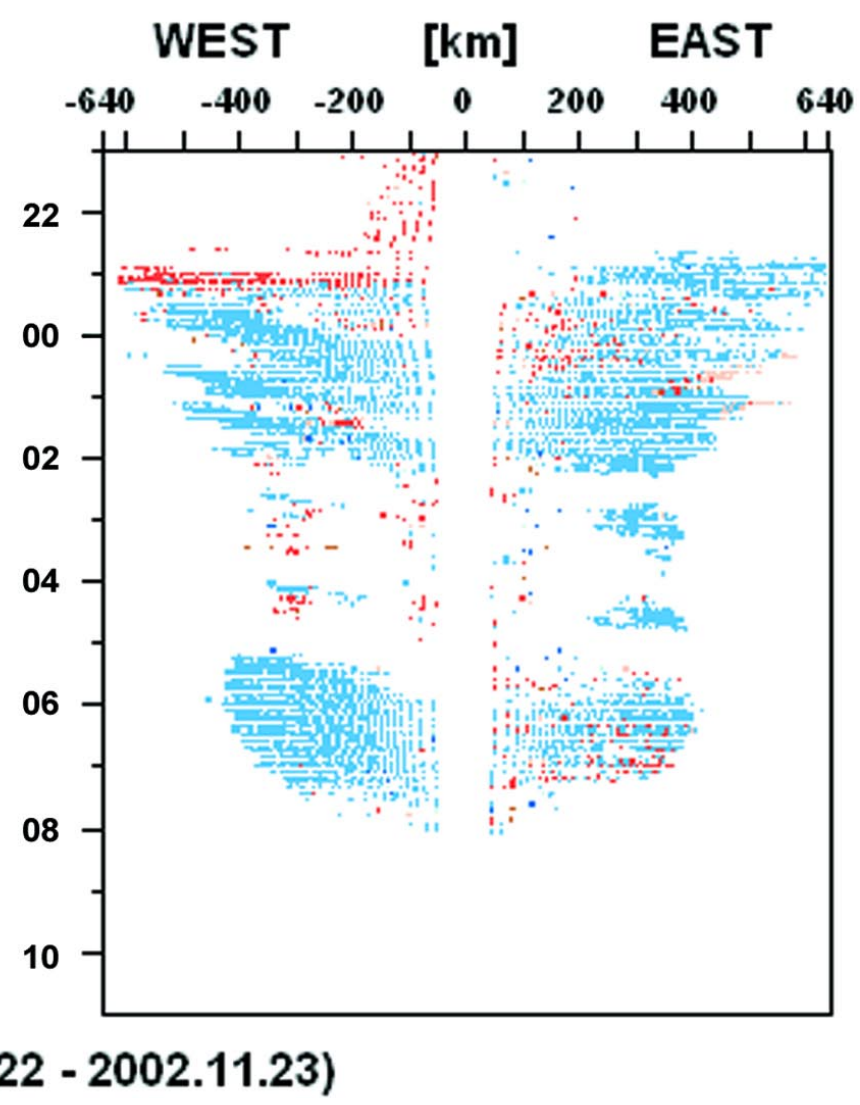

Fig. 7. Directograms for Cachimbo and Jicamarca on 22 November show the distances to the depletions observed in the ionograms.

profile is derived by using the measured scale height at the F2 peak and assuming a matching $\alpha$-Chapman density distribution (Reinisch and Huang, 2001).

\subsection{ESF development}

The ionograms usually sees an approaching depletion in the west about 30 to $60 \mathrm{~min}$ before it arrives overhead, depending on the eastward drift velocity. Measuring the radar ranges to the vertical and oblique echoes and the direction from which the echoes arrive, it is possible to calculate the approximate horizontal distances to the depletions and plot them as a function of time in a "directogram". The directogram shows the distance to the depletions in the west and east, and suppresses the vertical echoes. Figure 7 shows the directograms for 22 November at Jicamarca and Cachimbo. As expected, Cachimbo sees the development of depletions one hour before Jicamarca detects any. These disturbances persist for about $9 \mathrm{~h}$ at both locations, although at a reduced level at Cachimbo from 03:00 to 05:00 UT. Eastward displacement of the ESF depletions with its irregularity is clearly seen over Cachimbo, with the displacement velocity decreasing towards post midnight hours (LT=UT-3 h). Over Jicamarca such displacement velocity is not clearly defined. This behavior might suggest the existence of a longitudinal variation in the irregularity dynamics. It should be investigated if this longitudinal difference is the result of the moderate intensity magnetic disturbance (with $\Sigma K_{i p}=31$ ) that characterized this night.

We studied the occurrence of ESF at the three equatorial locations, Jicamarca in the west, Cachimbo, and Sao Luis in the east. Figure 8 shows the automatically generated display of observed range spread QF in $\mathrm{km}$ for a) October and b) November 2002. The ionogram cadence was $5 \mathrm{~min}$ at Jicamarca and Cachimbo, and $15 \mathrm{~min}$ at Sao Luis. A solid line underneath the data indicates that the sounder was operating. The averaged daily $K_{p}$ values in the bottom panel do not reveal any apparent correlation with the ESF activity. On most of the 61 days, ESF occurrence is the same for the three stations, but on 13 days, listed in the group "some" in Table 1, one or two of the sites are quiet. Only one day, 14 October (none), had quiet conditions at all three sites. For comparison Table 1 shows one example, October 10 (all), with all sites active. The table lists the observed range spread QF, the maximum vertical drift $V_{z}$ at the prereversal enhancement (Farley et al., 1986), and the maximum $\mathrm{F} 2$ peak height $h m F 2$; the average $K_{p}$ value is given for each of the days. High $V_{z}$ and large $h m F 2$ values are usually assumed to be preconditions for ESF development (Fejer et al., 1999) but our examples 

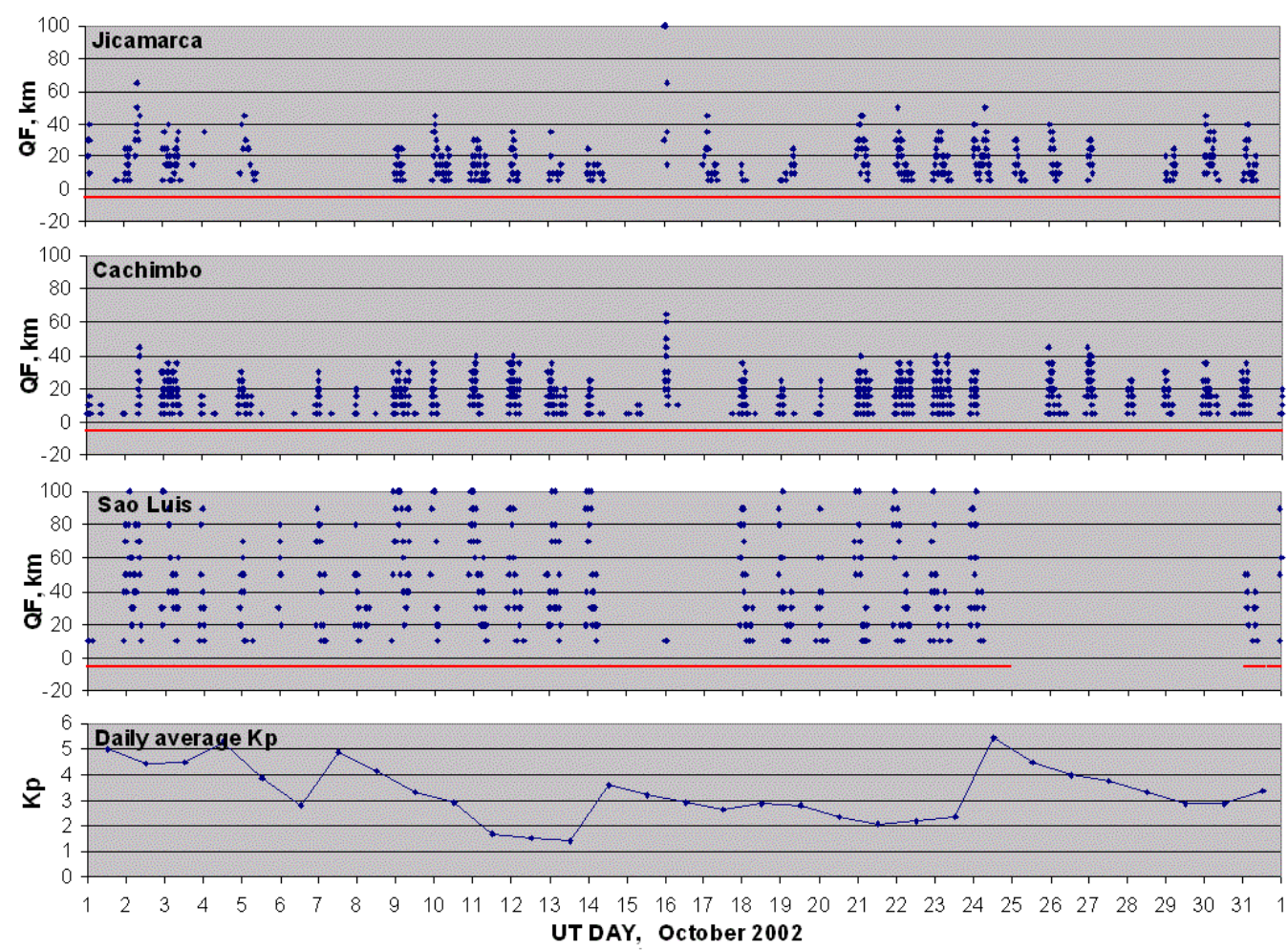

(a)
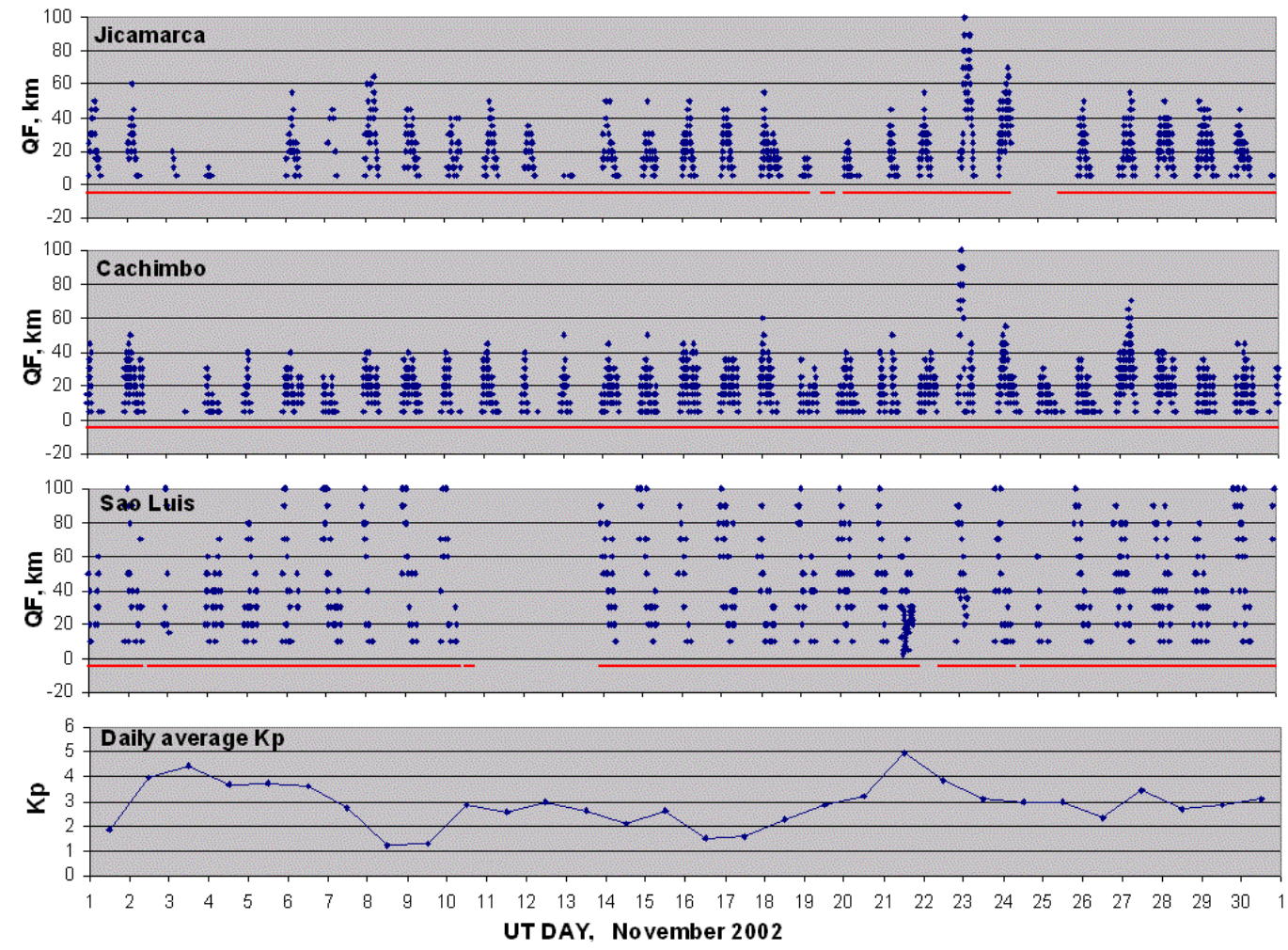

(b)

Fig. 8. Automatically detected range spread at Jicamarca, Cachimbo, and Sao Luis for (a) October and (b) November 2003. Underlining shows the times of digisonde operation. 
Table 1. Range spread, maximum vertical drift at prereversal enhancement, and the maximum F2 layer peak height for October and November 2002, grouped into all sites quiet (none), some but not all sites with ESF activity (some), and one example for all three sites active (all). A dash indicates "no data".

\begin{tabular}{|c|c|c|c|c|c|c|c|c|c|c|c|}
\hline \multirow[b]{2}{*}{ ESF } & \multirow[b]{2}{*}{ Date } & \multicolumn{3}{|c|}{$\begin{array}{r}\text { spread } F \\
\mathrm{~km}\end{array}$} & \multicolumn{3}{|c|}{$\max V_{z}$} & \multicolumn{3}{|c|}{$\begin{array}{c}\max h m F 2 \\
\mathrm{~km}\end{array}$} & \multirow[b]{2}{*}{ SL } \\
\hline & & $K_{p}$ & $\mathrm{Ji}$ & $\mathrm{Ca}$ & SL & $\mathrm{Ji}$ & $\mathrm{Ca}$ & SL & $\mathrm{Ji}$ & $\mathrm{Ca}$ & \\
\hline \multirow[t]{8}{*}{ none } & 14 October & $4-$ & 0 & 0 & 0 & 11 & 32 & 30 & 504 & 518 & 538 \\
\hline & 5 October & $5+$ & 0 & 0 & 80 & 16 & 42 & 29 & 480 & 567 & 588 \\
\hline & 6 October & $3-$ & 0 & 30 & 90 & 55 & 45 & 48 & 581 & 612 & 557 \\
\hline & 7 October & $5-$ & 0 & 20 & 80 & 56 & 50 & 37 & 552 & 614 & 638 \\
\hline & 15 October & $3+$ & 100 & 65 & 0 & 55 & 50 & 43 & 545 & 631 & 620 \\
\hline & 16 October & 30 & 45 & 0 & 0 & 72 & 31 & 27 & 640 & 560 & 551 \\
\hline & 19 October & $3-$ & 0 & 25 & 100 & 64 & 51 & 57 & 567 & 634 & 612 \\
\hline & 24 October & $5+$ & 35 & 0 & - & 34 & 29 & - & 520 & 485 & - \\
\hline \multirow[t]{6}{*}{ some } & 27 October & $4-$ & 0 & 25 & - & 68 & 37 & - & 510 & 552 & - \\
\hline & 2 November & 40 & 0 & 0 & 100 & 50 & 39 & 33 & 615 & 564 & 595 \\
\hline & 3 November & $4+$ & 0 & 30 & 70 & 72 & 41 & 32 & 542 & 620 & 640 \\
\hline & 4 November & $4-$ & 0 & 40 & 80 & 37 & 77 & 40 & 490 & 652 & 562 \\
\hline & 12 November & 30 & 0 & 50 & - & 50 & 64 & - & 560 & 673 & - \\
\hline & 18 November & $2+$ & 0 & 35 & 100 & 49 & 39 & 47 & 715 & 590 & 627 \\
\hline all & 10 October & 30 & 30 & 40 & 100 & 70 & 59 & 35 & 638 & 648 & 557 \\
\hline
\end{tabular}

Table 2. foEs values at Boa Vista / Campo Grande (the larger value) at the time of the prereversal enhancement on the days without ESF at Cachimbo.

\begin{tabular}{lllll}
\hline $\begin{array}{l}\text { Date } \\
2002\end{array}$ & $\begin{array}{l}\text { foEs }(22: 00 \mathrm{UT}) \\
\mathrm{MHz}\end{array}$ & $\begin{array}{l}\text { foEs }(22: 15 \mathrm{UT}) \\
\mathrm{MHz}\end{array}$ & $\begin{array}{l}\text { Time of } V_{z}, \max \\
\mathrm{UT}\end{array}$ & $\begin{array}{l}f o E s\left(\text { at time of } V_{z}, \max \right) \\
\mathrm{MHz}\end{array}$ \\
\hline 5 October & 2.4 & 2.3 & $22: 00$ & 2.4 \\
14 October & 4.7 & 7.9 & $22: 10$ & 7.7 \\
16 October & 3.9 & 2.6 & $22: 05$ & 2.6 \\
24 October & 3.4 & 3.8 & $21: 55$ & 2.4 \\
2 November & $>1.5$ & 4.3 & $22: 00$ & $>1.5$ \\
\hline
\end{tabular}

show that these conditions are not sufficient. There is no systematic difference in $V_{z}$ or $h m F 2$ at the sites with or without ESF occurrence.

\subsection{Effect of $E$-region conductivity}

It is often speculated that the field-line integrated Pedersen conductivity is affected by sporadic $E$ ionization at the $E$ region footprints of the magnetic field line through the $F$ region at the equator, and that $E s$ may short circuit the electric field necessary to lift the F2 layer preventing the Rayleigh-Taylor instability to grow. The two digisondes at Boa Vista in the north and Campo Grande in the south have monitored the $E s$ activity during the COPEX campaign close to the $E$-region intersection of the magnetic field line that crosses the equator at $350 \mathrm{~km}$ over Cachimbo. The foEs critical frequency distribution for 68 nights with ESF activity peaks between 2 and $3 \mathrm{MHz}$. Figure 9 gives the distribution at 22:00 UT, and $V_{z}$ at Cachimbo usually reaches its maximum values between 22:00 and 22:20 UT. The larger of the

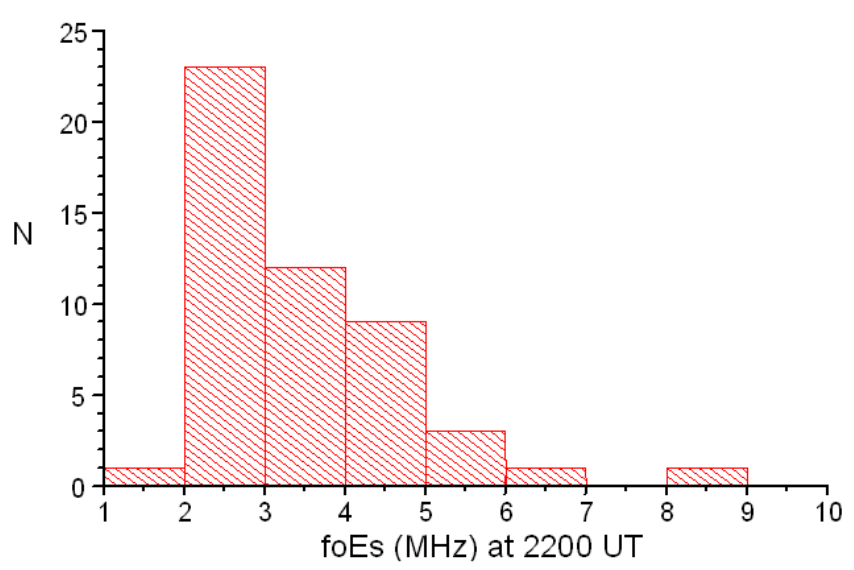

Fig. 9. Distribution of $f o E s$ values at Boa Vista/Campo Grande at 22:00 UT for ESF days at Cachimbo. 


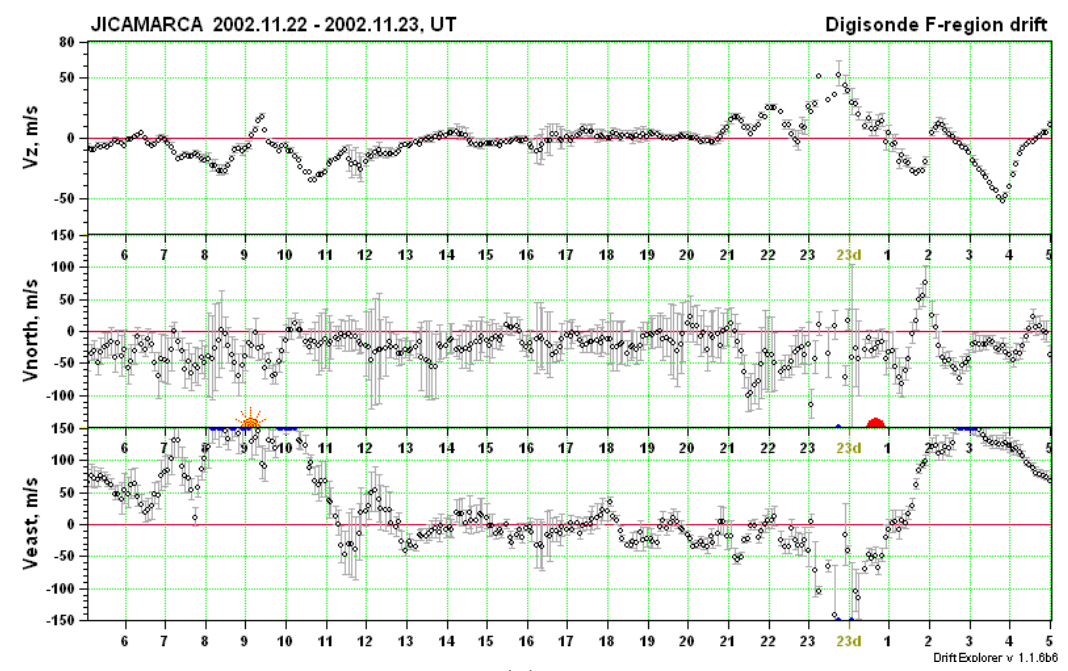

(a)

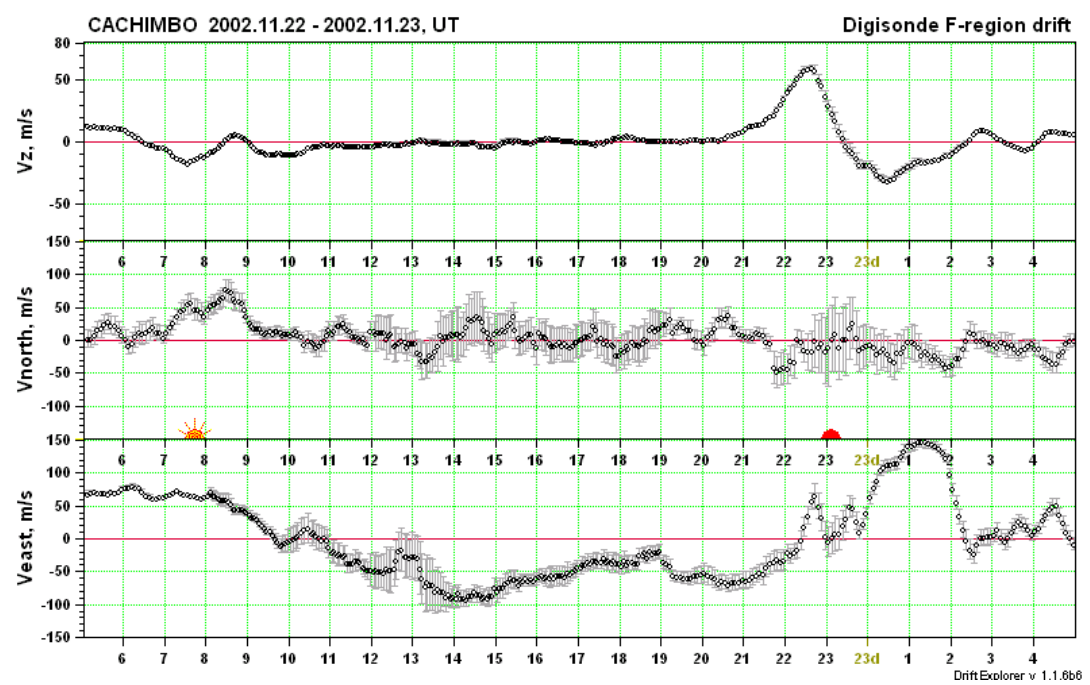

(b)

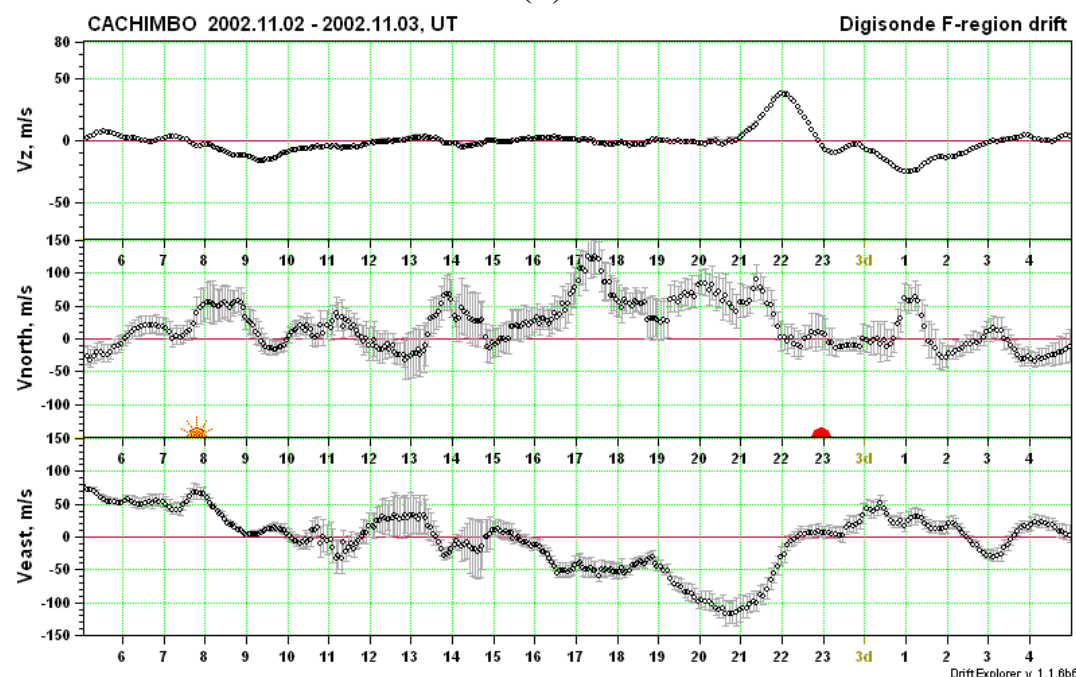

(c)

Fig. 10. Vertical, meridional, and zonal drift velocities on 22-23 November (strong ESF) at (a) Jicamarca and (b) Cachimbo, and (c) on 2-3 November (no ESF) at Cachimbo. 
foEs values observed at Boa Vista and Campo Grande was included in the statistics.

Table 2 summarizes the Es activity at Boa Vista and Campo Grande on the 5 quiet days at Cachimbo without ESF. Clearly the foEs values are not any larger on these days than on the 68 disturbed days. A preliminary conclusion is that the presence or lack of sporadic $E$ at the footprints of the magnetic field line plays no role in inhibiting or encouraging the development of equatorial spread $F$ at the magnetic equator.

\subsection{Equatorial $F$-region drift}

For the first time, all three components of the $F$-region drift were simultaneously measured by the digisondes at several equatorial sites. The velocity components are calculated from the line of site velocities (Doppler frequency shifts) of the skymap source points (Reinisch et al., 1998). Figures 10a and $10 \mathrm{~b}$ show the vertical, and the magnetic meridional and zonal velocities on 22 November, which had strong ESF activity at Jicamarca and Cachimbo. The error bars are shown in gray. For comparison, Fig. 10c shows the velocities at Cachimbo for 2 November when neither site observed ESF. On the quiet day, $V_{z}$ at Cachimbo reached a value of $40 \mathrm{~m} / \mathrm{s}$ compared to $65 \mathrm{~m} / \mathrm{s}$ on 22 November, but this is not a particularly small value and many days with smaller values did have ESF. The maximum $V_{z}$ at Jicamarca (not shown here) was about the same on these two days.

The horizontal components at Cachimbo show more significant differences on these two days. On 2 November just before sunset, the northward velocity reaches values above $100 \mathrm{~m} / \mathrm{s}$ and westward velocities of $120 \mathrm{~m} / \mathrm{s}$, and very low eastward velocities prevailed after the prereversal enhancement. At this stage of our analysis we have not yet done a systematic evaluation of the horizontal plasma flow. It is likely that the gravity waves, which may be required to trigger the instabilities (Valladares et al., 1983) could be identified with the drift measurements.

Acknowledgements. UML was in part supported by AFRL under contract AF19628-02-C-0092.

Topical Editor M. Lester thanks two referees for their help in evaluating this paper.

\section{References}

Abdu, M. A., Sobral, J. H. A., Batista, I. S., Rios, V. H., and Medina, C.: Equatorial spread-F occurrence statistics in the American longitudes: Diurnal, seasonal and solar cycle variations, Adv. Space Res., 22(6):851-854, 1998.

Abdu, M. A., Batista, I. S., Reinisch, B. W., de Souza, J. R., de Paula, E. R., Sobral, J. H. A., and Bullett, T, W.: Equatorial Spread F and Ionization Anomaly development as diagnosed from conjugate point observations (COPEX) in Brasil, XXIII IUGG General Assembly Sapporo, Japan, 30 June-11 July, 2003.

Anderson, D. N. and Mendillo, M.: Ionospheric conditions affecting the evolution of equatorial plasma depletions,. Geophys. Res. Lett., 10, 541-545, 1983.

Batista, I. S., Abdu, M. A., and Medrano, R. A.: 'Magnetic activity effects on range type spread-F and vertical plasma drift at Fortaleza and Huancayo as studied through ionosonde measurements and theoretical modeling, Ann. Geophys., 8(5), 357-364, 1990.

Bibl, K. and Reinisch, B. W.: The universal digital ionosonde, Radio Sci., 13, 519-530, 1978.

Farley, D. T, Bonelli, E., Fejer, B. G., and Larson, M. F.: The prereversal enhancement of the zonal electric field in the equatorial ionosphere, J. Geophys. Res. 91, 13 723-13 731, 1986.

Fejer, B. G., Scherliess, L., and De Paula, E. R.: Effects of the vertical plasma drift velocity on the generation and evolution of equatorial spread F, J. Geophys. Res. 104, 19854-19869, 1999.

Huang, X. and Reinisch, B. W.: Vertical total electron content from ionograms in real time, Radio Science, 36, 2, 335-342, 2001.

Reinisch, B. W.: Modern Ionosondes, in Modern Ionospheric Science, (Eds. Kohl, H., Rüster, R., and Schlegel, K., European Geophysical Society, 37191 Katlenburg-Lindau, Germany, 440-458, 1996.

Reinisch, B. W. and Huang, X.: Deducing Topside Profiles and Total Electron Content from Bottomside Ionograms, Adv. Space Res., 27, 1, 23-30, 2001.

Reinisch, B. W., Scali, J. L., and Haines, D. M.: Ionospheric drift measurements with ionosondes, Annali di Geofisica, 41, N. 56, 695-702, 1998.

Sales, G. S., Reinisch, B. W., Scali, J. L., Dozois, C., Bullett, T. W., Weber, E. J., and Ning, P.: Spread-F and the structure of equatorial ionization depletions in the Southern Anomaly region, J. Geophys. Res., 101, A12, 26 819-26 827, 1996.

Valladares, C. E., Hanson, W. B., McClure, J. P., Cragin, B. L.: Bottomside sinusoidal irregularities in the equatorial $F$-region, J. Geophys. Res. 88, 8025-8042, 1983.

Woodman, R. F. and La Hoz, C.: Radar observations of F-region equatorial irregularities, J. Geophys,. Res., 81, 5447-5461, 1976. 